12. Salemi A, Sedrakyan A, Mao J, Elmously A, Wijeysundera H, Tam DY, et al. Individual operator experience and outcomes in transcatheter aortic valve replacement. JACC Cardiovasc Interv. 2019;12:90-7.

13. Kundi H, Strom JB, Valsdottir LR, Elmariah S, Popma JJ, Shen C, et al. Trends in isolated surgical aortic valve replacement according to hospital-based transcatheter aortic valve replacement volumes. JACC Cardiovasc Interv. 2018;11: 2148-56.
14. Gonzalez AA, Dimick JB, Birkmeyer JD, Ghaferi AA. Understanding the volume-outcome effect in cardiovascular surgery: the role of failure to rescue JAMA Surg. 2014;149:119-23.

15. Likosky DS, Harrington SD, Cabrera L, DeLucia A 3rd, Chenoweth CE, Krein SL, et al. Collaborative quality improvement reduces postoperative pneumonia after isolated coronary artery bypass grafting surgery. Circ Cardiovasc Qual Outcomes. 2018;11:e004756.
See Article page 2046.

\section{Commentary: The importance of surgical case volume in the transcatheter era}

\author{
Pedro Catarino, MD, FRCS, Dominick Megna, MD, \\ and Joanna Chikwe, MD, FRCS
}

What cardiac surgeon does not enjoy performing a low-risk aortic valve replacement (AVR)? The patients really benefit and are appreciative. The surgery is quick and within every surgeon's technical comfort zone. It is often the first procedure over which a teacher and pupil bond. Exposure is generally excellent, allowing both teacher and trainee to be facile. However, indications for transcatheter aortic valve replacement (TAVR), which already include high- and intermediate-risk populations, are expanding to include low-risk patients. Most surgeons can claim zero mortality in low-risk patients. Unfortunately, this does not mean they have cracked the surgical holy grail; rather, they have not done enough cases yet, as the paper by Dewey and colleagues in this issue of the Journal shows. ${ }^{1}$

To evaluate the impact of case volume, the authors used a regional Society of Thoracic Surgeons database to identify

\footnotetext{
From the Department of Cardiac Surgery, Smidt Heart Institute, Cedars-Sinai Medical Center, Los Angeles, Calif.

Disclosures: Cedars-Sinai Medical Center receives honoraria from EdwardsLifesciences and Medtronic for speaker and consulting activity. The authors reported no conflicts of interest.

The Journal policy requires editors and reviewers to disclose conflicts of interest and to decline handling or reviewing manuscripts for which they may have a conflict of interest. The editors and reviewers of this article have no conflicts of interest.

Received for publication July 22, 2020; revisions received July 22, 2020; accepted for publication July 23, 2020; available ahead of print July 25, 2020.

Address for reprints: Joanna Chikwe, MD, FRCS, Department of Cardiac Surgery, Smidt Heart Institute, Cedars-Sinai Medical Center, Beverly Hills, Los Angeles, CA (E-mail: joanna.chikwe@cshs.org).

J Thorac Cardiovasc Surg 2022;163:2055-6 $0022-5223 / \$ 36.00$

Copyright (c) 2020 Published by Elsevier Inc. on behalf of The American Association for Thoracic Surgery

https://doi.org/10.1016/j.jtcvs.2020.07.076
}

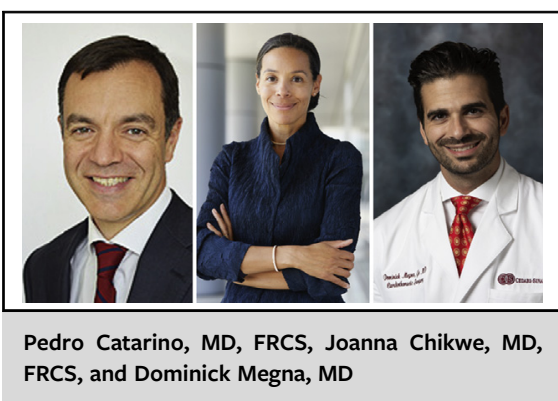

CENTRAL MESSAGE

Heart-team performance and appropriateness of care may have a greater impact on patient outcomes than case volume in the transcatheter era.

2066 low-risk patients who underwent isolated AVR. Centers performing more than 200 cases annually were classified as high-volume, whereas those performing fewer were classified as low volume. Just 3 of 29 hospitals in North Texas were high-volume, treating more than one half the patient population $(53 \%)$. The study revealed greater mortality in the low-volume cohort compared with the high-volume cohort (hazard ratio, 1.95; 95\% confidence interval, 1.2-3.2). Other quality surrogates also favored high-volume centers: postoperative renal failure, permanent pacemaker requirement, transfusion, and readmission rates.

Why is this? The authors highlight several factors, emphasizing institutional processes and resources, and "failure to rescue." The most resilient hospitals have robust processes and depth of staff, resulting in the ability to rescue patients who develop complications that might otherwise amplify into significant adverse outcomes, including mortality. ${ }^{2}$ There are just 3 centers in the high-volume group, which could be centers of excellence independently of 
their high-volume practices. Certainly, the consistency of outcome measures favoring the high-volume centers implies a quality factor operating at multiple levels.

In patients considered low risk, good results are expected; hence, the focus of adverse outcomes is frequently on the surgeon. This paper addresses neither individual surgeon volume nor institutional or individual cumulative experience. Some have suggested that surgeon volume may be more important than institutional volume: these authors have previously shown that high-risk patients undergoing AVR had improved outcomes at the hands of high-volume surgeons. ${ }^{3}$ As the indications for TAVR expand, there will be substantially fewer experienced, high-volume surgeons performing isolated AVR. Long-term durability for TAVR in low-risk populations remains unknown. The onus is on surgeons to maintain excellent outcomes and work closely with our cardiology colleagues in a heart-team approach to identify which subgroups of low-risk patients will derive the most benefit from each therapy. The authors' study adds to a growing body of evidence correlating outcomes with surgeon and institutional case volume across many procedures, including aortic and mitral valve surgery. ${ }^{4,5}$ However, appropriateness of care may be an even greater determinant of outcome: it may therefore be time for our focus to shift from scrutinizing individual providers to examining the overall performance of our heart-teams.

\section{References}

1. Dewey TM, Herbert MA, Prince SL, Bowers BS. Influence of surgical volume on outcomes in low risk patients having isolated surgical aortic valve replacement. $J$ Thorac Cardiovasc Surg. 2022;163:2046-52.e2.

2. Ahmed EO, Butler R, Novick RJ. Failure-to-rescue rate as a measure of quality of care in a cardiac surgery recovery unit: a five-year study. Ann Thorac Surg. 2014; 97:147-52.

3. Dewey TM, Herbert MA, Ryan WH, Brinkman WT, Smith R, Prince SL, et al. Influence of surgeon volume on outcomes with aortic valve replacement. Ann Thorac Surg. 2012;93:1107-13.

4. Chikwe J, Cavallaro P, Itagaki S, Seigerman M, Diluozzo G, Adams DH. National outcomes in acute aortic dissection: influence of surgeon and institutional volume on operative mortality. Ann Thorac Surg. 2013;95:1563-9.

5. Badhwar V, Vemulapalli S, Mack MA, Gillinov AM, Chikwe J, Dearani JA, et al. Volume-outcome association of mitral valve surgery in the United States. JAMA Cardiol. July 1, 2020 [Epub ahead of print]. 